\title{
Corte Suprema de Justicia de la Nación
}

Causa: Defensor del Pueblo de la Nación c/ Estado Nacional y otro s/ proceso de conocimiento

Buenos Aires, 26 de diciembre de 2018

Autos y Vistos;

Considerando:

$1^{\circ}$ ) Que a fs. 2658/2666 se presenta el señor Orlando Charole, por derecho propio, en su condición de integrante de la etnia Qom y actual presidente de la "Fundación América Originaria", a solicitar que se admita su inmediata intervención como litisconsorte en este proceso (artículo 90, inciso $2^{\circ}$ del Código Procesal Civil y Comercial de la Nación) y, en tal carácter, pide -en lo sustancial- la ampliación territorial de la medida cautelar dictada en este proceso "en materia alimentaria y sanitaria al pueblo Wichi principalmente, cuyas comunidades se encuentran en el Departamento Güemes" en las "localidades Miraflores, Techat, Nueva Pompeya, Nueva Población, Comandancia Frías, Las Hacheras, Wichi El Pintado, Sauzal, Sauzalito, Vizcacheral, Tartagal, •Cevilar, Tres Pozos y Fortín Belgrano", mediante efectivas acciones positivas del Estado Nacional y la Provincia del Chaco. en forma concurrente.

Agrega nota de los presidentes de asociaciones Y referentes del Pueblo Wichi.

Explica que la medida vigente en esta causa alcanza a localidades habitadas por comunidades Qom y que la ampliación pretendida se refiere a las comunidades Wichi, ya que son estos los pueblos que residen -principalmente- en la región norte del departamento de General Güemes.

\section{EL ESTADO COMO GARANTE DE LOS DERECHOS DE LOS PUEBLOS ORIGINARIOS EN ARGENTINA}

\author{
THE ARGENTINIAN STATE AS GUARANTOR OF ABORIGINAL'S RIGHTS
}

\section{MARÍA FLORENCIA BLANCO PIGHI}

RESUMEN:

Los derechos humanos de los pueblos originarios, entre ellos, el derecho a la salud, son reconocidos por la Constitución Argentina, por tratados internacionales ratificados por nuestro país, por la normativa interna y por las constituciones provinciales. La Corte Suprema de Justicia de la Nación, mediante el fallo en análisis, establece que la protección de estos derechos debe asegurarse por la vía más idónea, y que, al existir una acción de amparo en curso, la medida cautelar de interposición más reciente, debe ser rechazada.

\footnotetext{
1 Abogada y Profesora en Ciencias Jurídicas, egresada de la Facultad de Derecho de la Universidad Nacional de Córdoba. Docente tutor de la Facultad de Derecho U.N.C. en el marco del programa: "Acompañamiento a las trayectorias estudiantiles" de la Secretaría de Asuntos Estudiantiles, U.N.C. Adscripta de la Cátedra "B" de Privado VII, Facultad de Derecho U.N.C. Docente de Política y Derecho Educacional del Profesorado en ciencias jurídicas (UNC). Jefa de Trabajos prácticos de la Cat. "A" en la materia Privado VIII, Facultad de Derecho y Ciencias Sociales en la U.C.C. - Mail: florblancopighi@gmail.com / ORCID iD: https://orcid.org/0000-0001-9324-4036.
} 
Señala que el pronunciamiento dictado en estos autos tuvo el propósito de "garantizar a las comunidades indígenas ubicadas en el sudeste del Departamento General Güemes y noroeste del Departamento Libertador General San Martín una real y efectiva calidad de vida digna que les garantice el ejercicio de los derechos a la vida, salud, asistencia médico-social, alimentación, . agua potable, educación, vivienda, bienestar general, trabajo, inclusión social, entre otros, y que tales derechos sean satisfechos de manera continua y permanente". Sin embargo -continúa-, su instrumentación no habría logrado contener la tuberculosis en un gran porcentaje de la población a su vez -según afirma-, habrían aumentado los casos de desnutrición crónica infantil de grado I (uno), persistiendo además el Mal de Chagas.

Luego de denunciar que los habitantes del impenetrable chaqueño están padeciendo una grave situación sanitaria, alimentaria y hospitalaria, informa que en el año 2015, en su carácter de diputado de la Provincia del Chaco presentó el proyecto de ley $\mathrm{n}^{\circ} 45$ declarando "El estado de emergencia hospitalaria y sanitaria de las comunidades indígenas del pueblo Qom y Wichi ubicadas en la regiones sanitarias $\mathrm{n}^{\circ} 5 \mathrm{y} \mathrm{n}^{\circ} 6 \mathrm{del}_{\text {Chaco (Villa }}$ Río Bermejito, El Espinillo, Miraflores, Pampa del Indio, Misión Nueva Pompeya, El Sauzalito y Comandancia Frías)", el cual -sostiene- se encuentra actualmente en la Comisión de Desarrollo Humano y Salud de la Legislatura Provincial.

Asimismo, pone de resalto que ya en el cargo de Presidente del Instituto del Aborigen Chaqueño (IDACH) que actualmente ocupa, dictó la resolución n 16 del 22 de enero de 2018 por la cual se declaró "La emergencia sanitaria de los pueblos indígenas del Departamento General Güemes de la Provincia del Chaco".

Aduce que pese a la adopción de dichas medidas y a la cautelar dictada por esta Corte, las necesidades básicas de las comunidades del impenetrable chaqueño aún no habrían sido satisfechas

Solicita, en definitiva, que se restablezca la asistencia de la que resultaron en su momento beneficiarios los miembros de las comunidades indígenas del sudeste del Departamento General Güemes y el noroeste del Departamento de General San Martín como sus zonas aledañas, ya que, afirma, nunca se reanudó y el estado

\section{ABSTRACT:}

The Argentinian Constitution, the international human rights treaties ratified by Argentina, the argentine internal regulations and the constitution of several provinces, recognize the aboriginal's human rights, including the right to health. In the judgment in analysis, the Argentinian Supreme Court of Justice, states that the protection of those rights needs to be accomplish by the most suitable way. When a legal protection action is in curse, the most recently filed action must be rejected.

Palabras Claves: Pueblos originarios; derecho a la salud; protección constitucional; acción de amparo.

Key Words: Aboriginal people; right to health; constitutional protection; legal protection action.

\section{Introducción}

El 26 de diciembre de 2018 nuestra Corte Suprema de Justicia de la Nación resolvió no hacer lugar a una acción de amparo interpuesta por el Defensor del Pueblo en contra del Estado Nacional Argentino y del Estado Provincial Chaco por existir otra causa, en etapa de ejecución, en la que se había hecho lugar a un pedido cautelar similar.

La diferencia entre ambos procesos, radica en el territorio comprendido, ya que la petición de amparo que nos ocupa, solicitaba la ampliación territorial de la medida cautelar dictada en este proceso "en materia alimentaria y sanitaria al pueblo Wichi, principalmente, cuyas comunidades se encuentran en el Departamento Güemes" en las localidades de: Miraflores, Techat, Nueva Pompeya, Nueva Población, Comandancia Frías, Las 
de vulnerabilidad, indefensión y ausencia de alimentos en dichas comunidades persiste.

$2^{\circ}$ ) Que sin entrar a considerar la admisibilidad de la intervención pretendida por el peticionario, los términos de la presentación que antecede imponen destacar que paralelamente al trámite de este proceso cautelar, en jurisdicción de la Provincia del Chaco se sustanció la causa "Instituto del Aborigen Chaqueño (I.D.A.CH.) y pueblos indígenas Qom, Wichi y Mocoví c/ Gobierno de la Provincia del Chaco y/o quien resulte responsable s/ acción de amparo" (expediente $\mathrm{N}^{\circ} 454$, año 2007), del registro del Juzgado Civil y Comercial $\mathrm{n}^{\circ} 6$, de la Primera Circunscripción Judicial.

De los antecedentes que obran en este expediente (fs. 1028/1029) puede extraerse que en la causa mencionada recayó pronunciamiento definitivo que hizo lugar a la acción de amparo promovida por el Instituto del Aborigen Chaqueño (I.D.A.CH.) y los pueblos indígenas Qom, Wichi y Mocoví, en virtud del cual se ordenó a la Provincia del Chaco a que, a través de sus órganos pertinentes, de conformidad con la distribución constitucional y legal de organización y ejercicio del poder público, arbitre los recaudos a fin de dar estricto e inmediato cumplimiento a lo prescripto por el artículo 37 de la Constitución provincial, 75 inciso 17 de la Constitución Nacional, Convenio 169 de la O.I.T. y el Acta Acuerdo celebrada con la demandante con fecha 19 de agosto de 2006, como así también el deber de informar de manera documentada cada una de las medidas que a tal fin se adopten. Las normas referidas coinciden -en lo sustancial- con el derecho invocado por el peticionario en el punto 3 de su presentación.

De acuerdo a lo que surge del sistema de consultas de expedientes del Poder Judicial de la Provincia del Chaco, el referido fallo fue confirmado por la Sala Primera de la Cámara de Apelaciones Civil y Comercial y por el Superior Tribunal de Justicia de la Provincia (sentencia No 599 del 20 de diciembre de 2012), y actualmente se encuentra en etapa de ejecución.

$3^{\circ}$ ) Que tal antecedente permite considerar que la cuestión que hace al fundamento del pedido en examen

Hacheras, Wichi El Pintado, Sauzal, Sauzalito, Vizcacheral, Tartagal, Cevilar, Tres Pozos y Fortín Belgrano, mediante efectivas acciones positivas del Estado Nacional y la Provincia del Chaco, en forma concurrente.

Que, sin perjuicio del rechazo de la medida cautelar interpuesta, la Corte Suprema de Justicia de la Nación, procedió a requerirles al Estado Provincial y Nacional que en el plazo de treinta días hábiles actualicen, de conformidad con el programa marco presentado, en forma concreta y precisa, el estado de ejecución de los programas de salud, alimentación, asistencia sanitaria, provisión de agua potable, fumigación y desinfección de las regiones alcanzadas.

Cabe preguntarse entonces, si la resolución del más alto tribunal argentino, vulnera los derechos humanos de los pueblos originarios de, en este caso, el territorio de la Provincia de Chaco.

\section{La Población indígena en Argentina}

Resulta necesario, conocer, en primera medida, cuales son los pueblos originarios que habitan el suelo argentino, cuyos derechos humanos, entre ellos, el acceso a la salud, queremos proteger.

En este sentido, resulta imperioso poner de manifiesto que la nómina de pueblos aborígenes se construye en el marco del proceso dinámico de auto reconocimiento que viven los Pueblos Indígenas en nuestro país, y por ello, no son un número cerrado, es decir, varía constantemente, para lo cual el Estado Argentino, y los distintos estados provinciales, realizan estudios y censos, para así determinar la cantidad de población y las problemáticas que sufren, entre otras cuestiones de interés. 
está comprendida en la que ha sido sometida a juzgamiento por el Instituto del Aborigen Chaqueño -ente autárquico gubernamental encargado de velar por las necesidades de los pueblos Originarios de la Provincia del Chaco (arts. 22 y ss. ley 3258) y del cual es presidente en la actualidad el peticionario- y los pueblos indígenas Qom, Wichi y Mocoví ante la jurisdicción local, y que el objeto de la causa citada abarca de manera sustancial la pretensión cautelar formulada en la presentación que antecede.

De modo que la tutela de los derechos de los pueblos indígenas que habitan las localidades referidas de la región norte del territorio chaqueño, debería procurarse y encauzarse contra el Estado provincial en el marco de la ejecución de la citada sentencia dictada por la jurisdicción local.

En tanto no se ha hecho mención del referido proceso, ni tampoco se han expresado los motivos por los cuales la petición no se ha canalizado por esa vía, es dable concluir que no corresponde dar curso en estas actuaciones a la solicitud formulada.

$4^{\circ}$ ) Que sin perjuicio de ello, en relación a la afirmación de que se habría discontinuado la asistencia dispuesta por decisión de este Tribunal en el pronunciamiento de fs. 52/55 (Fallos: 330:4134), y al tiempo transcurrido desde los informes presentados a fs. 2460/2461 (Provincia del Chaco) y 2501, 2503/2504 (Estado Nacional), ordenados por resolución del Tribunal de fecha 3 de octubre de 2017, con carácter previo a la decisión atinente a la competencia que pronunciará el Tribunal, requiéraseles a la Provincia del Chaco y al Estado Nacional que en el plazo de 30 días hábiles actualicen, de conformidad con el programa marco presentado a fs. 1102, en forma concreta y precisa, el estado de ejecución de los programas de salud, alimentación, asistencia sanitaria, provisión de agua potable, fumigación y desinfección de las regiones alcanzadas por la medida cautelar decretada en el citado decisorio de fs. 52/55.

Por ello, se resuelve: 1) No hacer lugar a la solicitud formulada. 2) Requerir a la Provincia del Chaco y al Estado Nacional, con carácter previo a la decisión atinente a la competencia que pronunciará el Tribunal, que en el

EL Registro Nacional de Comunidades Indígenas (RENACl) que se construye bajo el criterio de auto reconocimiento en el Instituto Nacional de Asuntos Indígenas (INAI), ha publicado que en Argentina, se han establecido los siguientes Pueblos Originarios: Atacama, Chané, Charrúa, Chorote, Chulupí, Comechingón, Diaguita, Diaguita Calchaquí, Guaraní, Huarpe, Kolla, Lule, Mapuche, Mocoví, Selk'nam (Ona), Ocloya, Omaguaca, Pilagá, Rankulche, Tapiete, Tehuelche, Tilián, Toba, Tonocoté, Vilela y Wichí.

La mayoría de estos pueblos se distribuyen en las provincias de Chaco y Misiones, razón por la cual, el fallo en análisis deviene de fundamental importancia.

\section{Los pueblos originarios y la legislación argentina}

Desde la conformación del Estado Argentino, existió una discusión sobre el lugar que debían ocupar los pueblos originarios. Durante mucho tiempo, se continuó con las políticas de exterminio y exclusión heredadas de la conquista, como por ejemplo la campaña al desierto y distintas estrategias militares que procuraban la apropiación de tierras para la conformación y delimitación del territorio argentino.

En coherencia con este tipo de políticas, existió durante muchos años, una marcada ausencia normativa en nuestro país, en torno a los pueblos originarios.

La reforma constitucional de 1994, modifica sustancialmente esta mirada, incorporando en el art. 75 inc. 17 de nuestra Carta Magna una normativa muy clara: "Reconocer la preexistencia étnica y cultural de los pueblos indígenas argentinos. Garantizar el respeto a su identidad y el derecho a una educación bilingüe e intercultural; reconocer la personería Jurídica de sus comunidades, y la posesión y propiedad comunitarias de las tierras que tradicionalmente ocupan; y regular la entrega de otras aptas y suficientes para el 
plazo de 30 días hábiles actualicen, de conformidad con el programa marco presentado a fs. 1102, en forma concreta y precisa, el estado de ejecución de los programas de salud, alimentación, asistencia sanitaria, provisión de agua potable, fumigación y desinfección de las regiones alcanzadas por la medida cautelar decretada en el decisorio de fs. 52/55, a cuyo fin cúrsense las correspondientes notificaciones por Secretaría.

Parte actora: Defensor del Pueblo de la Nación, representado por los doctores Daniel Bugallo Olano, Horacio Eduardo Esber y Anselmo Agustín Sella.

Parte demandada: Estado Nacional, representado por los doctores Sonia Haydeé Donati, María Alicia Gramajo, Fernando Zuberbuhler, Alejandro Enrique Scarano.

Provincia del Chaco, representada por los doctores Eduardo Aníbal Fernández Floriani y José Miguel Braceras, con el patrocinio letrado del señor Fiscal de Estado, doctor Luis Alberto Meza.

Instituto del Aborigen Chaqueño (presentado como tercero), representado por los señores Orlando Charole y Eigidio Luis Roberto García, con el patrocinio de la doctora María Lorena Gutiérrez Villar.

Orlando Charole (presentado como tercero), por sus propios derechos, con el patrocinio letrado del doctor Juan Carlos Baldomero Pérez.

desarrollo humano; ninguna de ellas será enajenable, transmisible ni susceptible de gravámenes o embargos. Asegurar su participación en la gestión referida a sus recursos naturales y a los demás intereses que los afecten. Las provincias pueden ejercer concurrentemente estas atribuciones."

Esta norma constitucional, es ampliada y complementada por el art. 18 del Código Civil y Comercial de la Nación, que entró en vigencia el primero de agosto del año 2015, que reconoce, en idéntico sentido, estos derechos de los pueblos originarios.

Dentro de nuestro ordenamiento interno, asimismo, se sancionaron varias normas en relación a esta temática, entre ellas: la ley 23.302 sobre Política Indígena y Apoyo a las Comunidades Aborígenes (modificada por ley 25.799), la Ley 24.956 que establece el autoreconocimiento de la identidad indígena en el Censo de 2001 y la ley 26.160 declara la emergencia en materia de posesión y propiedad comunitaria indígena (prorrogada por ley 26.554).

En el caso de la primera ley mencionada, que fue el primer triunfo legislativo en materia de derechos de los aborígenes, sancionada en el año 1985, se regula, en su capítulo VI, el derecho a la salud de las poblaciones indígenas, en los arts. 18, 19, 20 y 21. A su vez, resulta de vital importancia, porque dicha norma crea el Instituto Nacional de Asuntos Indígenas (INAI).

A su vez, algunas provincias también regulan las cuestiones relacionadas a los pueblos originarios en sus constituciones locales, siguiendo esa línea, la constitución provincial chaqueña establece en su art. 37: "La Provincia reconoce la preexistencia de los pueblos indigenas, su identidad étnica y cultural; la personería jurídica de sus comunidades y organizaciones; y promueve su protagonismo a través de sus propias instituciones; la propiedad comunitaria inmediata de la tierra que tradicionalmente ocupan y las otorgadas 
en reserva. Dispondrá la entrega de otras aptas y suficientes para su desarrollo humano, que serán adjudicadas como reparación histórica, en forma gratuita, exentas de todo gravamen. Serán inembargables, imprescriptibles, indivisibles e intransferibles a terceros. El Estado les asegurará: a) La educación bilingüe e intercultural. b) La participación en la protección, preservación, recuperación de los recursos naturales y de los demás intereses que los afecten y en el desarrollo sustentable. c) Su elevación socio-económica con planes adecuados. d) La creación de un registro especial de comunidades y organizaciones indigenas."

\section{La normativa internacional}

Nuestro país ha ratificado una gran cantidad de tratados internacionales que protegen los derechos humanos para todas las personas, a varios de ellos les ha dado incluso jerarquía constitucional en el año 1994 a través del art. 75 inc. 22 de la Constitución Nacional. Sin dudas, al ser vulnerado cualquier derecho humano de cualquier persona, sin distinción alguna de su origen étnico ni cultural, los mecanismos de protección internacional entran en acción.

Sin perjuicio de ello, Argentina ha ratificado normas internacionales específicas en relación a los pueblos originarios, entre las cuales se puede mencionar: el Convenio 169 de la Organización Internacional del Trabajo (OIT) sobre Pueblos Indígenas y Tribales en Países Independientes (ratificado por ley 24.071 en el año 1992), el Convenio sobre Diversidad Biológica (ratificado por ley 24.375)y el Convenio Constitutivo del Fondo para el Desarrollo de los Pueblos Indígenas en América Latina y el Caribe (aprobado por ley 24.544).

En idéntico sentido, la Organización de Naciones Unidas (O.N.U.) en el año 2007 proclama la Declaración sobre los Derechos de los Pueblos Indígenas, la que implica un compromiso político internacional de derechos humanos para la protección de los derechos individuales y colectivos de los pueblos indígenas.

La propia O.N.U. ha establecido que esta declaración "Es un documento exhaustivo que aborda temas como los derechos colectivos, los derechos culturales y la identidad, y los derechos a la salud, la educación, la salud, y el empleo entre otros. La Declaración enfatiza el derecho de los pueblos indígenas de preservar y fortalecer sus propias instituciones, culturas y tradiciones y de trabajar por su desarrollo de acuerdo a sus aspiraciones y necesidades. La Declaración sin duda favorecerá a los pueblos indígenas en sus esfuerzos por combatir la discriminación y el racismo."

En el artículo 24 de dicha Declaración se reconoce el derecho de los pueblos indígenas a sus propias medicinas tradicionales y a mantener sus prácticas de salud. Las medicinas tradicionales de los pueblos indígenas fueron, durante mucho tiempo, consideradas sin valor científico. ${ }^{3}$

\section{La protección del derecho a la salud de los pueblos originarios de Argentina}

El derecho a la salud es un derecho humano universalmente reconocido, que no admite ninguna distinción de género, origen étnico y racial, edad, orientación sexual, etc. Es decir, que para que sea efectivamente gozado por cualquier habitante, los servicios sociales y de salud no deben discriminar el acceso de los indígenas, y sí ofrecerles por lo

2 https://www.un.org/development/desa/indigenous-peoples-es/declaracion-sobre-los-derechos-de-los-pueblos-indigenas.html.

3 Garay, Oscar E. El derecho a la salud de los pueblos originarios o indígenas. Disponible en: http://www.salud.gob.ar/dels/entradas/el-derecho-la-saludde-los-pueblos-originarios-o-indigenas. 
menos el mismo servicio que a cualquier otra persona de la población.

Argentina tiene una vasta trayectoria en la defensa de los derechos humanos, no solo desde la reforma constitucional de 1994, con la incorporación de tratados internacionales sobre esta temática, los que han adquirido jerarquía constitucional. En cuanto a los pueblos originarios, nuestro país, al menos normativamente, los ha protegido, ratificando instrumentos internacionales y también mediante su normativa interna.

En el año 2016, se creó el Programa Nacional de Salud para los Pueblos Indígenas, a través de la Resolución 1036-E/2016, que tiene como objetivo mejorar la cobertura de salud y las condiciones de accesibilidad al Sistema Público de Salud de las Comunidades Indígenas de todo el país, desde una perspectiva intercultural. ${ }^{4}$

En este orden de políticas públicas, en el año 2017, el Ministerio de Salud, dependiente del Poder Ejecutivo Nacional, lanzó una publicación denominada "Interculturalidad y Salud", pensada para capacitar a los trabajadores en el servicio primario de atención de salud, en torno a cómo garantizar su derecho de acceso a la salud. En este documento se plantea que:

"Para considerar la situación de salud de los pueblos originarios no basta con conocer los datos duros de población, modos de vida, accesibilidad al sistema y enfermedades (datos incompletos, por cierto), sino que se hace necesario comprender que estas comunidades manejan un concepto propio de salud, que define su modo de cuidarla y que, muchas veces, colisiona con medicina tradicional. (...) La concepción de los pueblos indígenas respecto a la salud, está ligada a una perspectiva integral del mundo, se entiende entonces como el bienestar biológico, psicológico, social y espiritual del individuo y de su comunidad en condiciones de equidad. Es decir que desde la perspectiva de los pueblos indígenas la salud se concibe como un bienestar integral que incluye no solo la dimensión física, psicológica y social, sino también la espiritual."”

En este orden de ideas, se ha dicho que la interculturalidad es concebida como proceso de democratización y reorganización del Estado, para una nueva relación con los Pueblos Originarios. Se deriva de esto que no se trata únicamente de un programa de elementos culturales a tener en cuenta para no discriminar o para tolerar, sino de la construcción política de estas nuevas relaciones. ${ }^{\text {? }}$

Cabe preguntarnos si, en materia de protección de derechos, la mera existencia de normativa aplicable, alcanza a los fines de su efectiva concreción. La práctica nos ha demostrado que no, que las normas, en muchos casos no son respetadas, no solo por los particulares sino, también, en ocasiones, por el propio estado. Es en esas oportunidades en las que entra a tallar el Poder Judicial.

En el caso en cuestión, la Corte Suprema de Justicia de la Nación evalúa la procedencia de una acción de amparo, a los fines de ampliar el territorio afectado a la emergencia sanitaria y alimentaria de los pueblos originarios de la Provincia de Chaco. Estableciendo que, al existir otra acción similar (casi idéntica) en etapa de ejecución, correspondía rechazar la acción de amparo interpuesta, sin perjuicio de un pedido de informes sobre el estado de situación.

\footnotetext{
4 https://www.argentina.gob.ar/salud/pueblosindigenas.

5 Disponible en: http://www.msal.gob.ar/images/stories/bes/graficos/0000001067cnt-eps-interculturalidad-salud_2017.pdf.

6 Interculturalidad y salud. Programa Médicos Comunitarios Equipos de Salud del Primer Nivel de Atención. Ministerio de Salud. Presidencia de la Nación. Año 2017.

7 Díaz, H.: Interculturalidad, pueblos originarios y salud: reflexiones para un debate pendiente. Manuscrito, 2011.
} 


\section{Conclusiones}

Para finalizar, es necesario retomar el planteo inicialmente esbozado: ċla resolución del más alto tribunal argentino, vulnera los derechos humanos de los pueblos originarios de la Provincia de Chaco?

La respuesta que surge de todo lo analizado con anterioridad, es negativa. La Corte Suprema de Justicia de la Nación, rechaza la acción de amparo, por existir en etapa de ejecución otra acción de amparo, con un objeto casi idéntico e interpuesta por las mismas partes, resultando esta última la vía más idónea a la que hace alusión el art. 43 de la Constitución Nacional.

Que, sin embargo, la Corte, sin deslindarse del problema, planteando únicamente el rechazo de la medida cautelar interpuesta, le exige al estado provincial y nacional, en un plazo de treinta días hábiles, que se le informe de forma concreta y precisa, el estado de ejecución de los programas de salud, alimentación, asistencia sanitaria, provisión de agua potable, fumigación y desinfección de las regiones alcanzadas por la medida cautelar decretada en el decisorio invocado (Fallos: 330:4134).

La decisión del más alto tribunal argentino resulta relevante porque, respetando el mandado constitucional de protección a los pueblos originarios y la función del Estado de ser garante de sus derechos, establece cuales son las vías procesales idóneas y adecuadas para esta defensa.

Al existir otra acción de amparo ya admitida, con su etapa de ejecución en curso, cualquier planteo, entre las mismas partes, tendiente a la ampliación territorial de la emergencia sanitaria y alimentaria, debe ser canalizada por esta vía.

Resulta necesario puntualizar que, los derechos humanos de los pueblos originarios, quedan garantizados mediante este fallo, no solo al derivar el reclamo a la vía correspondiente, sino también con la exigencia de informes al Estado Nacional Argentino y al Estado Provincial de Chaco. 